\title{
IMPACT OF A POSSIBLE LOCAL WIND CHANGE ON THE WAVE CLIMATE IN THE UPPER RÍO DE LA PLATA
}

\author{
WALTER C. DRAGANI ${ }^{\mathrm{a}, \mathrm{b}, \mathrm{c}, *}$ and SILVIA I. ROMERO ${ }^{\mathrm{a}, \mathrm{b}}$ \\ a Departamento Oceanografía, Servicio de Hidrografía Naval and ESCM-INUN, Av. Montes de Oca 2124 (C1270ABV) Ciudad \\ Autónoma de Buenos Aires, Buenos Aires, Argentina \\ b Departamento Ciencias de la Atmósfera y los Océanos, Facultad de Ciencias Exactas y Naturales, Universidad de Buenos Aires, \\ (1428) Ciudad Universitaria, Pabellón II, 2do. piso, Ciudad Autónoma de Buenos Aires, Buenos Aires, Argentina \\ c CONICET, Consejo Nacional de Investigaciones Científicas y Técnicas, Argentina, Rivaduvia 1917 (C1033AAJ), Ciudad Autónoma \\ de Buenos Aires, Buenos Aires, Argentina \\ Received 30 July 2003 \\ Revised 17 March 2004 \\ Accepted 19 March 2004
}

\begin{abstract}
The aim of the present work is to give a quantitative assessment of the change in mean wave parameters in the upper Río de la Plata (RDP) by considering a possible change in local winds. A statistical analysis of the sea and swell in the outer RDP, as well as the computation and analysis of their propagation and transformation throughout the intermediate and upper regions, reveal that refraction, shoaling and friction effects diminish wave heights by $94.9 \%$. Consequently, the predominant wave climate in the upper RDP could only be described considering wind waves generated locally (sea). The present wave climate (directional wave heights and periods) in the upper RDP is estimated by the hindcasting methodology based on 10-year statistics of winds measured at 'Aeroparque Jorge Newery' meteorological station. A possible future scenario is sketched for which wind frequencies and intensities for the easterly directions are respectively $30 \%$ and $10 \%$ higher than the present values. The results for the upper RDP show that mean easterly wave heights will increase by $0.12 \mathrm{~m}(13 \%)$ relative to present values $(0.90 \mathrm{~m})$ and their frequencies will increase by $30 \%$ (from 18.4 to $23.9 \%$ ), producing larger total heights. Therefore, the coast of Buenos Aires city will be more frequently exposed to wave effects, giving rise to intensified associated littoral processes. The mean period for easterly waves will not change significantly (less than 4\%, from 5.3 to $5.5 \mathrm{~s}$ ). The results obtained are a first approximation to the problem, suggesting that within the upper RDP the wave climate is very sensitive to the predicted change in the wind field. Copyright (C) 2004 Royal Meteorological Society.
\end{abstract}

KEY WORDS: wave climate; Río de la Plata; wind change; wave hindcasting; wave height trend

\section{INTRODUCTION}

The Río de la Plata (RDP) is a shallow and extensive estuary located on the eastern coast of South America at approximately $35^{\circ} \mathrm{S}$ (Figure 1). It has a northwest (NW)-southeast (SE) general orientation and it is formed by the confluence of two of the most important rivers of South America: the Paraná and the Uruguay. The main characteristics of this estuary are its shallowness and its increasing width (Balay, 1961). The estuary has a funnel shape approximately $300 \mathrm{~km}$ long that narrows from $220 \mathrm{~km}$ at its mouth to $40 \mathrm{~km}$ at its upper end. The RDP can be divided into three regions: upper, with an averaged depth of less than $5 \mathrm{~m}$; intermediate, 5-10 m deep, occupied by several shallow sand banks; and an outer region with depths ranging from 10 to $20 \mathrm{~m}$. Throughout its system of channels the RDP estuary is the main maritime access to the Argentinian and the Uruguayan republics. Even though the most important cities and ports, including both capitals (Buenos Aires and Montevideo) and many of the industrial centres and resorts of both countries, are on the RDP margins, a reliable wave climate for the RDP estuary is not available.

* Correspondence to: Walter C. Dragani, Departamento Oceanografía, Servicio de Hidrografía Naval, Av. Montes de Oca 2124, (C1270ABV) Ciudad Autónoma de Buenos Aires, Buenos Aires, Argentina; e-mail: dragani@hidro.gov.ar 


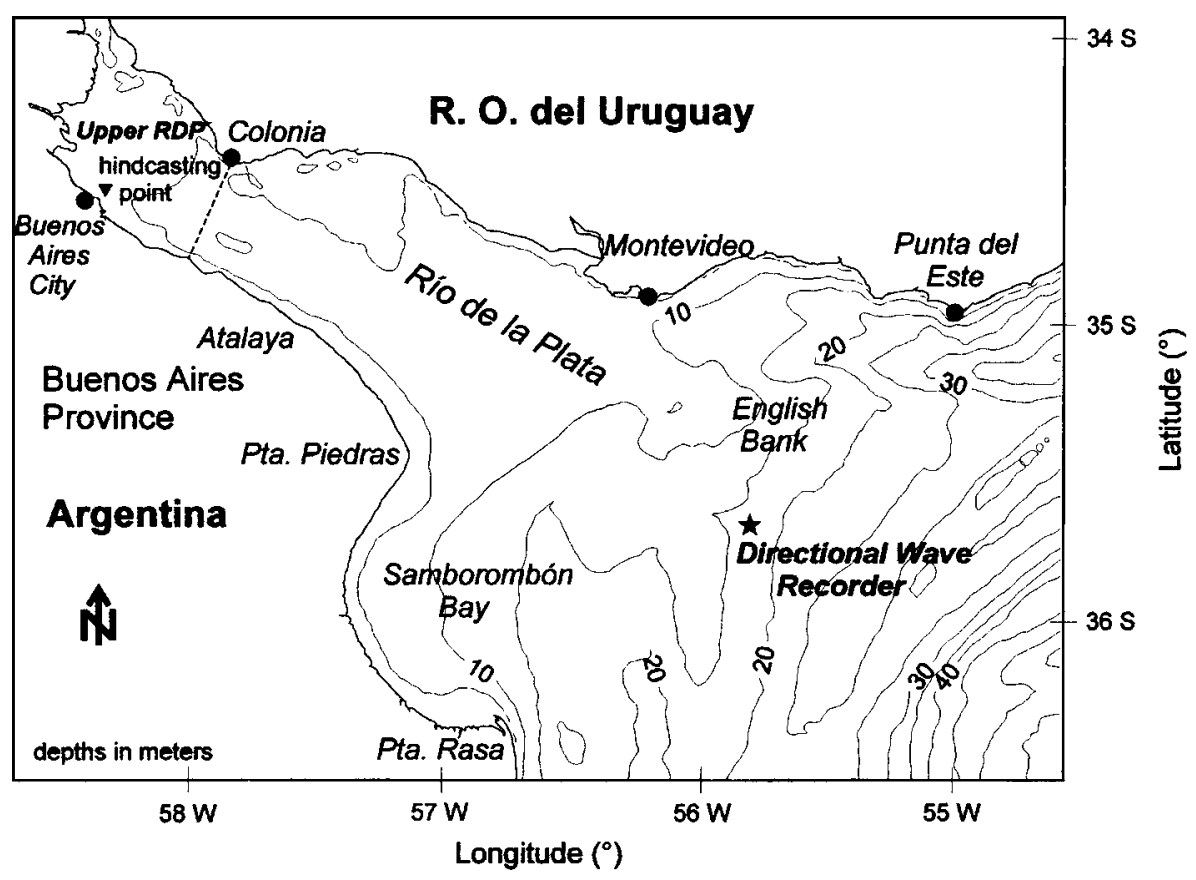

Figure 1. Río de la Plata estuary. Hindcasting point and directional wave recorder location are indicated. $5 \mathrm{~m}$ depth contours are depicted

There are four wave data sources available to build a wave climate: (i) altimeter measurements from ERS-1, ERS-2 and TOPEX instruments (Cotton and Carter, 1994; Woolf et al., 2002); (ii) voluntary observing ships (VOS; Wilkerson and Earle, 1990; Gulev et al., 2003); (iii) wave model hindcasts (Sterl et al., 1998; Cox and Swail, 2001); and (iv) in situ observations (buoys). The first three provide global coverage, but there are serious problems with the data quality. Altimeter waves are dependent on the retrieval algorithms used and are not available for very shallow coastal waters (as is the case of the intermediate and upper RDP). Model hindcasts depend on the quality of winds employed and the wave model performance. Moreover, global wave models have insufficient resolution to give reliable wave parameters in the intermediate and upper RDP. Furthermore, to our knowledge there have been no wave model applications in the RDP estuary. VOS waves are visual measurements and quite inaccurate. There is one single location in the RDP where direct measurements were gathered using a Datawell Waverider directional wave recorder.

Escobar et al. (2003) showed that the western border of the South Atlantic high is slowly moving southward. They applied principal component methodology to a monthly mean sea-level pressure data set from the National Centers for Environmental Prediction-National Center for Atmospheric Research reanalysis (1951-2000) in a domain defined by $25-45^{\circ} \mathrm{S}$ and $67.5-45^{\circ} \mathrm{W}$. Their results for the last decades show a slight trend in the western border of the South Atlantic semi-permanent high-pressure system to move towards the south. This displacement has produced increased frequencies of easterly winds over the RDP estuary.

The aim of the present work is to give a quantitative assessment of the changes in mean wave heights and periods in the upper RDP by considering a possible future change in local winds. The first step was to analyse whether waves observed in the outer RDP could propagate toward the NW and reach the upper region. When waves did not reach this zone, wave climate in the upper RDP could only be represented by the sea. Assuming, that the slight changes in both frequency and intensity of local winds found by Escobar et al. (2003) will occur, they should affect the future wave climate within the upper RDP. This has not been addressed up to the present. For the upper RDP, present and future mean directional wave heights are estimated and compared herein. Finally, changes in mean heights and periods, together with some energetic considerations, are studied. We also discuss briefly the possible impacts on littoral processes and sediment transport. 


\section{DATA}

Wave measurements were recorded between June 1996 and November 2001 with a Datawell Waverider directional wave recorder in the outer RDP at latitude $35^{\circ} 40^{\prime} \mathrm{S}$ and longitude $55^{\circ} 50^{\prime} \mathrm{W}$ (Figure 1). The series includes four gaps of 1, 5, 8 and 16 months long; therefore, during the 5 years spanning the recording period, a total of 11297 records were valid (equivalent to 3 years). A single-point vertical mooring with some metres of rubber cord ensures sufficient symmetrical horizontal buoy response for small motions at low frequencies (Datawell, 1997). The directional Waverider measures the accelerations and computes the translations caused by wave motion, from which the wave direction is calculated. All calculations to determine the translations in fixed coordinate directions (north $(\mathrm{N})$, west $(\mathrm{W})$ and vertical), as well as the determination of the spectral and directional data, are done inside the instrument. The instrument was programmed to measure 20 min sea-level records with a $0.5 \mathrm{~s}$ sampling interval, every $2 \mathrm{~h} 40 \mathrm{~min}$.

Based on the spectral analysis of these data, Anschütz (2000) showed that the wave climate in the outer RDP is a combination of swell (waves generated far away, not related to local winds) and sea (waves generated by local winds). The analysis of these data for the outer RDP revealed predominant heights between 0.5 and $1.5 \mathrm{~m}$. When sea prevailed, periods were between 4 and $6 \mathrm{~s}$, when swell prevailed they were between 10 and $12 \mathrm{~s}$.

The wave parameters analysed in this paper are: (i) the energy-based wave height $H_{\mathrm{MO}}$ (computed as four times the square root of the 20 min sea-surface variance); (ii) the peak spectral period $T_{\mathrm{P}}$; and (iii) the wave direction $\left(1.5^{\circ}\right.$ resolution) given in degrees $\left(0^{\circ}\right.$, waves coming from the $\mathrm{N} ; 45^{\circ}$, from the northeast (NE); etc.). Possible changes in the wave parameters in the outer RDP cannot be studied through the analysis of monthly and interannual variability of mean heights (Bacon and Carter, 1991, 1993), since this series is not long enough and it has some long gaps.

\section{WAVE CONDITIONS IN THE UPPER RDP}

First, sea and swell heights and periods in the outer RDP were statistically analysed from direct observations (Section 3.1). Second, we studied the propagation and transformation of sea and swell from the outer RDP throughout the intermediate and upper regions in order to assess whether outer waves could reach the upper RDP (Section 3.2). Third, the wave conditions (i.e. mean $H_{\mathrm{MO}}$ and $T_{\mathrm{P}}$ ) in the upper region of the RDP were estimated (Section 3.3).

\subsection{Sea and swell conditions in the outer RDP}

Directional bi-dimensional distributions $\left(H_{\mathrm{MO}}-T_{\mathrm{p}}\right)$ were made using the Waverider data described in Section 2. Table I shows the number of occurrences for the eight directions analysed. For example, the $\mathrm{N}$ direction $\left(0^{\circ}\right)$ includes all the cases of waves propagating with directions between $337.5^{\circ}$ and $22.5^{\circ}$, the east $(\mathrm{E})$ direction $\left(45^{\circ}\right)$ between $22.5^{\circ}$ and $67.5^{\circ}$, etc. The SE direction followed by the $\mathrm{E}$ and south $(\mathrm{S})$ directions were the main directions of propagation, with $41 \%, 28 \%$ and $14 \%$ of occurrences respectively. Frequencies for the rest of the directions were equal to or lower than 5\%. The bi-dimensional distribution for the direction with the largest number of occurrences, i.e. SE, is shown in Figure 2. Two areas with very large number of events around periods of $10 \mathrm{~s}$ and heights of $0.8 \mathrm{~m}$ (swell) and periods of $5 \mathrm{~s}$ and heights of $1.25 \mathrm{~m}$ (sea) can be clearly identified.

Considering the general orientation (NW-SE) of the RDP and its shallowness, only the waves propagating from the SE could reach the upper RDP. Thus, swell and sea propagating from the outer to the upper RDP would be the long and short swell respectively, within the intermediate and upper regions. Refraction, shoaling and bottom friction transformations of long and short waves propagating throughout the intermediate and upper RDP are considered next. 
Table I. Number of events and percentage of occurrence for each of the eight wave directions analysed within the outer RDP estuary

\begin{tabular}{lcc}
\hline Direction & No. of events & Occurrence (\%) \\
\hline N & 278 & 2 \\
NE & 237 & 2 \\
E & 3161 & 28 \\
SE & 4646 & 41 \\
S & 1607 & 14 \\
SW & 539 & 5 \\
W & 420 & 4 \\
NW & 409 & 4 \\
\hline
\end{tabular}

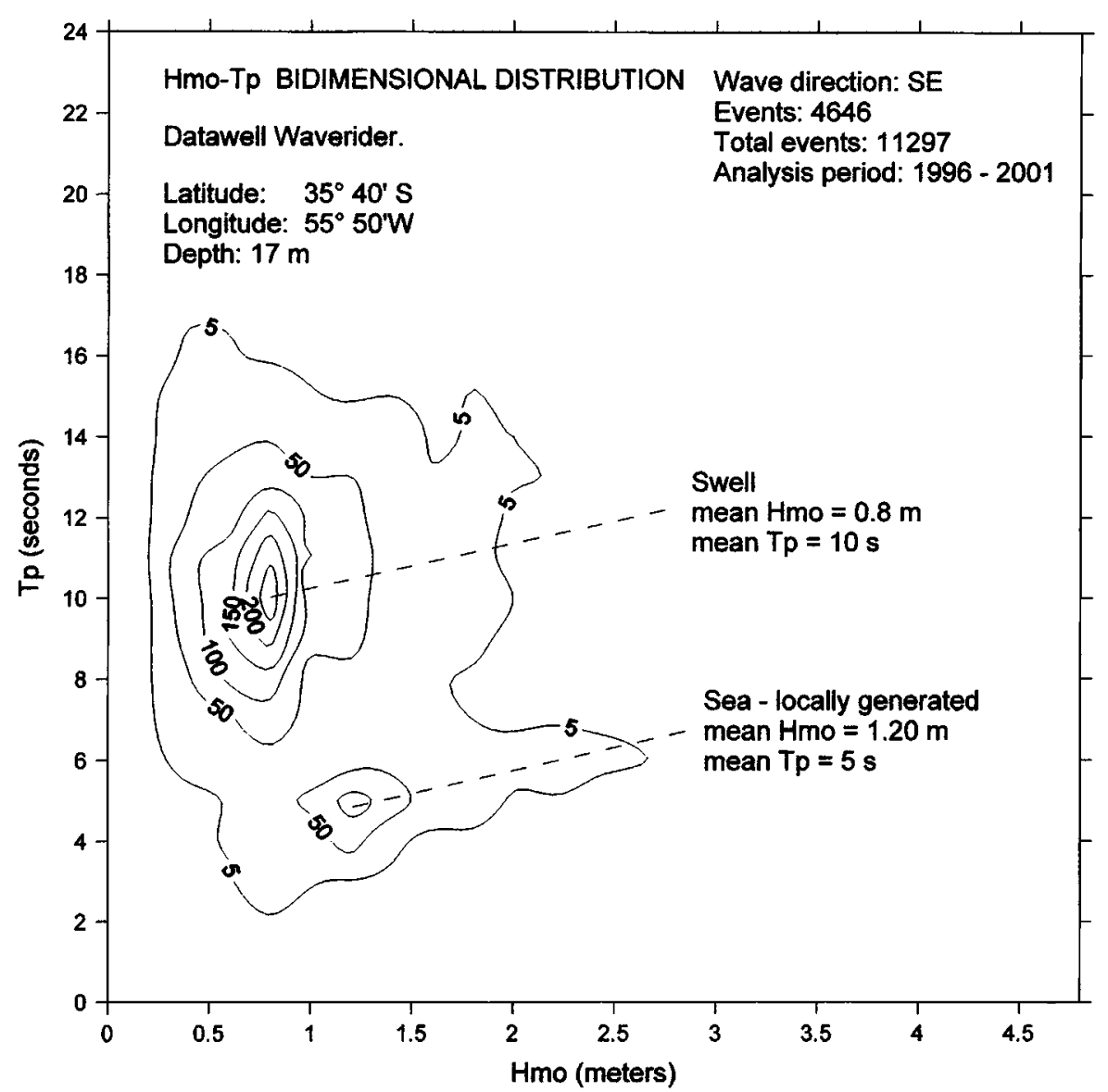

Figure 2. Bi-dimensional distribution of heights and periods. Mean sea and swell characteristics are indicated

\subsection{Swell conditions in the upper RDP}

Wave propagation and transformation from the outer RDP towards the coast of Buenos Aires were analysed by means of a numerical model of wave transformation (Dragani and Mazio, 1991). The wave number, a parameter that must satisfy the modified dispersion relation at any point (Watanabe, 1982), was computed by considering realistic bathymetry and stationary but spatially variable current fields corresponding to flood and 
ebb tide conditions. Refraction, shoaling and friction effects along the wave ray were computed based on a bathymetric grid of $1 \mathrm{~km}$ spatial resolution obtained from the nautical charts SHN (1999 a,b). In the model applied, the refraction coefficient was computed with the classical methodology given by Griswold (1963). The shoaling coefficient was based on the wave celerity at any point, by applying linear wave theory. Bottom friction removes energy from waves by interaction between oscillatory wave-induced currents on the seabed, sediments and bed forms. Friction effects always diminish the wave height along the ray. In order to obtain the rate at which energy was removed from waves, we adopted the formulation given by Putnam and Johnson (1942). The friction coefficient adopted was 0.005, suggested by CARP (1992) as being the most adequate value for the RDP. Energy dissipation along the ray was computed using an integral expression given by Vincent and Carrie (1988). Herein, we assumed that waves propagate as swell from the outer RDP towards the upper RDP under non-locally generated wave conditions. Two different swell conditions were analysed: short swell, associated with sea in the outer RDP $(T<6 \mathrm{~s})$ and long swell, associated with swell in the outer $\operatorname{RDP}(T>6 \mathrm{~s})$. Refraction diagrams were built using initial heights of $1.25 \mathrm{~m}$ in all cases, though similar conclusions can be obtained using different heights within the observed range. The results show that shallowwater effects (especially refraction) were less evident over short swell. Therefore, the short swell becomes the most likely wind wave to reach the intermediate and upper RDP. Outputs from the transformation model corresponding to short swell coming from the SE are shown in Figure 3, which depicts a refraction diagram for 20 rays directed from the outer RDP towards the NW. An initial separation of $3 \mathrm{~km}$ was adopted between rays.

Shallow waters and banks were identified as areas where wave breaking occurred. Caustics (crossing rays) seemed to have an important role in wave propagation and transformation towards the upper RDP, producing consequent wave attenuation. Figure 3 also shows that rays diverged strongly at the intermediate RDP, producing two areas of caustics: one located between Punta Piedras and Atalaya (near the coast of Buenos Aires), and another SE of Colonia (near the coast of Uruguay). In order to analyse the wave transformation between the outer and upper regions, an additional ray, reaching the upper RDP, was computed (dashed line in Figure 3). The refraction $K_{\mathrm{R}}$, shoaling $K_{\mathrm{S}}$ and friction $K_{\mathrm{F}}$ coefficients computed for the end point of the ray,

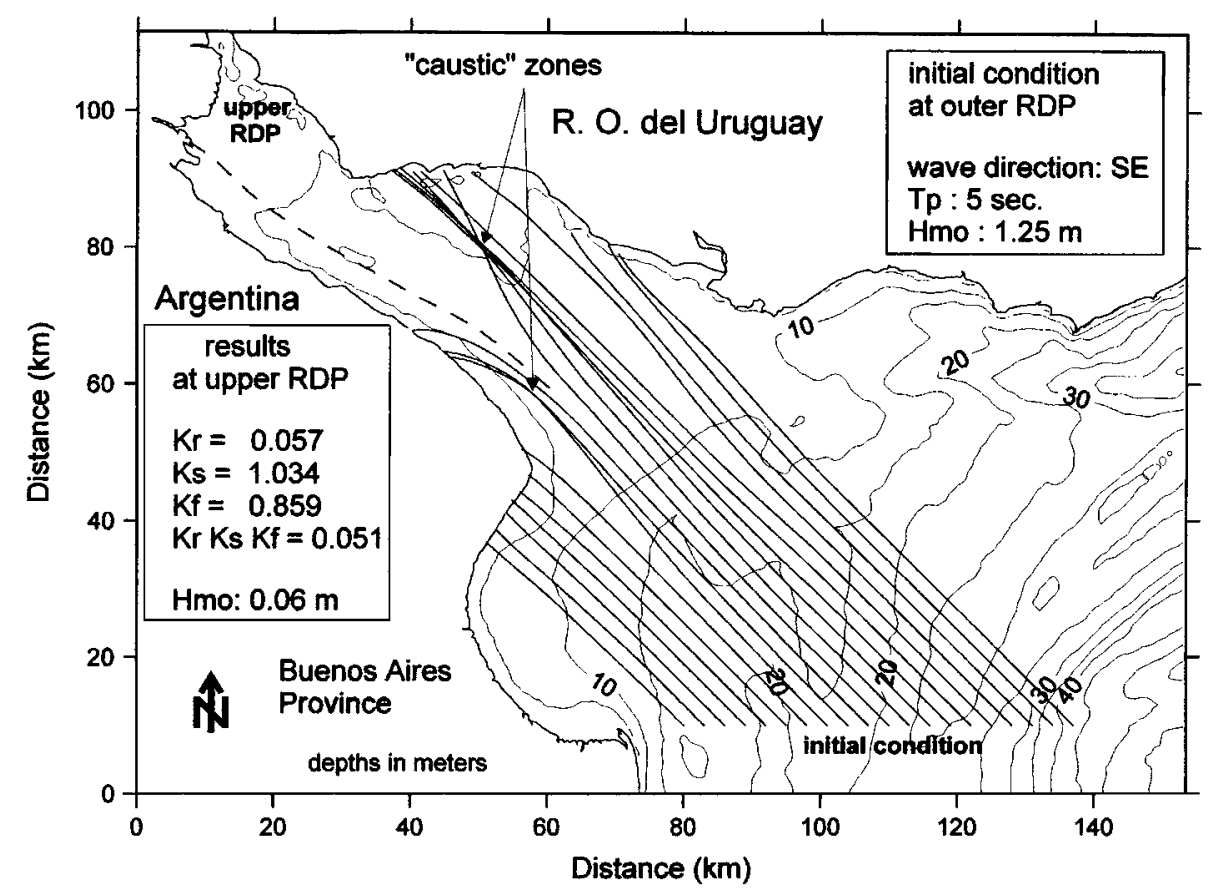

Figure 3. Refraction diagram corresponding to waves coming from SE. Refraction, shoaling and dissipation coefficients are indicated. An intermediate ray (dashed line) reaching the upper RDP is included 
within the upper RDP, were $0.057,1.034$ and 0.859 respectively. The transformation coefficient, computed as the product of the three aforementioned coefficients, was 0.051 . Therefore, heights of waves propagating from the outer to the upper RDP were $94.9 \%$ attenuated by refraction, shoaling and friction effects. According to our results, the predominant wave climate within the upper RDP could be described by considering only those wind waves generated locally (sea).

\subsection{Sea conditions in the upper RDP}

In the particular case of the upper RDP, where wind waves have never been measured, a preliminary study on wave conditions is of special interest. In this sense, the wave hindcasting method (CERC, 1984) and the improvements given by CERC (2002) can be reasonably applied to give a first approximation of the wave parameters. This wave parameter model was applied at a coastal point near Buenos Aires city (Figure 1). Under fetch-limited conditions, winds have blown constantly long enough for wave heights at the end of the fetch to reach equilibrium. Under duration-limited conditions, the wave heights are limited by the length of time the wind has been blowing. These two conditions represent an asymptotic approximation to the general problem of wave growth. In most cases the wave growth pattern is a combination of the two cases. The equations used in this work are present in $\operatorname{CERC}(1984,2002)$ and were obtained by simplifying the equation used to develop the parametric model of Hasselmann et al. (1976).

The methodology was applied in shallow waters, off the surf zone, where the local depth is approximately $2 \mathrm{~m}$. Monthly wind statistics (SMN, 1992) were obtained from hourly data gathered at "Aeroparque Jorge Newery' meteorological station, located on the coast of Buenos Aires city (Figure 1). The parameters required for hindcasting are fetch and wind speed, the latter being representative of the average value over the fetch. The wave parameters computed are $H_{\mathrm{MO}}$ and $T_{\mathrm{P}}$. Fetch-limited conditions were considered herein, given the nature of the meteorological data available and considering the geographical characteristics of the upper RDP. Under these conditions, it was supposed that winds had been blowing long enough for wave heights to reach equilibrium at the end of the fetch. For the SE and NW directions (approximately parallel to the coastline) the wave parameters might have been slightly overestimated because narrow fetch conditions were not considered. Directional mean winds used in the wave hindcasting are presented in Table II. The E direction presents the highest frequency (18.4\% of cases). The N, NE, SE and S directions each present similar frequencies (ranging from 11.5 to $15.8 \%$ ) and southwest $(\mathrm{SW}), \mathrm{W}$ and $\mathrm{NW}$ directions and calms are least frequent, with values ranging from 6.5 to $7.8 \%$. Directional mean wind intensity (from 4.6 to $6.1 \mathrm{~m} \mathrm{~s}^{-1}$ ) is quite uniform for all directions.

CERC (2002) recommended applying deep-water methodology for hindcasting in shallow waters. Shallowwater formulae are quite close to those of deep-water wave growth for the same wind speeds, up to a point where an asymptotic depth-dependent wave height is attained. Therefore, it is convenient to disregard bottom friction effects on wave growth in shallow waters. Evidence from Bouws et al. (1985) also indicates that wave

Table II. Directional mean wind and frequency of occurrence (\%) obtained from data gathered at 'Aeroparque Jorge Newery' meteorological station located on the coast of Buenos Aires city. Also included are directional fetch, heights and periods obtained by hindcasting

\begin{tabular}{lcccccc}
\hline Index & Direction & Frequency $(\%)$ & Mean wind $\left(\mathrm{m} \mathrm{s}^{-1}\right)$ & Fetch $(\mathrm{km})$ & $H_{\text {MO }}(\mathrm{m})$ & $T_{\mathrm{P}}(\mathrm{s})$ \\
\hline 1 & $\mathrm{~N}$ & 15.8 & 4.9 & 36 & 0.49 & 3.5 \\
2 & $\mathrm{NE}$ & 11.5 & 4.6 & 45 & 0.50 & 3.7 \\
3 & $\mathrm{E}$ & 18.4 & 4.9 & 125 & 0.90 & 5.3 \\
4 & $\mathrm{SE}$ & 12.2 & 5.8 & 150 & 1.22 & 5.5 \\
5 & $\mathrm{~S}$ & 13.7 & 5.1 & 2 & 0.15 & 1.4 \\
6 & $\mathrm{SW}$ & 7.5 & 5.2 & 2 & 0.13 & 1.4 \\
7 & $\mathrm{~W}$ & 6.8 & 5.2 & 22 & 0.12 & 1.4 \\
8 & $\mathrm{NW}$ & 6.6 & - & - & -41 & 3.1 \\
9 & Calms & 6.5 & & & - & - \\
\hline
\end{tabular}


spectra for shallow waters do not seem to have a noticeable dependence on variations in bottom sediments. Consequently, it is recommended that deep-water wave growth formulae be used for all depths, with the constraint that no peak spectral period can grow past a limiting value $T_{\mathrm{P}, \mathrm{MAX}}$, as shown by Vincent (1985), given by

$$
T_{\mathrm{P}, \mathrm{MAX}}=9.78 \sqrt{\frac{h}{g}}
$$

where $h$ is the mean depth and $g$ is the acceleration due to gravity.

Table II presents the mean wind intensity, frequency, and fetch for the eight directions analysed and the heights $\left(H_{\mathrm{MO}}\right)$ and periods $\left(T_{\mathrm{P}}\right)$ estimated by hindcasting. For each direction analysed, the fetch was measured as the distance from the hindcasting point to the coast (Figure 1), except for the case of the SE direction, where a $150 \mathrm{~km}$ fetch was adopted beginning at the imaginary line joining Punta Piedras and Montevideo. The largest heights and the longest periods resulted for the SE $(1.22 \mathrm{~m}$ and $5.5 \mathrm{~s}$ respectively) and for the E $(0.9 \mathrm{~m}$ and $5.3 \mathrm{~s}$ respectively). The shortest heights and periods resulted for the $\mathrm{W}(0.12 \mathrm{~m}$ and $1.4 \mathrm{~s})$, for the $\mathrm{SW}(0.13 \mathrm{~m}$ and $1.4 \mathrm{~s})$ and for the $\mathrm{S}(0.15 \mathrm{~m}$ and $1.4 \mathrm{~s})$.

\section{PRESENT AND FUTURE MEAN WAVE CONDITIONS IN THE UPPER RDP}

\subsection{Present mean wave conditions}

The directional mean heights and periods presented in Table II were used to compute the non-directional mean height $\overline{H_{\mathrm{MO}}}$ and period $\overline{T_{\mathrm{P}}}$ in the upper RDP near the coast of Buenos Aires city by means of:

$$
\begin{gathered}
\overline{H_{\mathrm{MO}}}=\sum_{i=1}^{8} H_{\mathrm{MO}, i} f_{i} / 100 \\
\overline{T_{\mathrm{P}}}=\sum_{i=1}^{8} T_{\mathrm{P}, i} f_{i} / 100
\end{gathered}
$$

where $i$ is an index related to the wind direction ( $i=1$ is $\mathrm{N}, i=2$ is NE, etc.) and $H_{\mathrm{MO}, i}, T_{\mathrm{P}, i}$ and $f_{i}$ are respectively the heights, periods and frequencies shown in Table II. The mean height and period obtained from Equations (2) and (3) are $0.52 \mathrm{~m}$ and $3.3 \mathrm{~s}$ respectively. Both values should only be considered as a rough approximation of the mean wave condition within the upper RDP, near Buenos Aires city.

\subsection{Future mean wave conditions}

Experiments with a global circulation model (GCM) run with SRS A2 scenarios indicate that the observed southward shift of the western border of the South Atlantic high will continue through the 21st century; consequently, both wind frequency and intensity for the E direction will increase in the future (Barros, 2003). In the present study we analyse a possible scenario with increases of $30 \%$ and $10 \%$ respectively in the $\mathrm{E}$ wind frequency and intensity. Likewise, in this hypothetical scenario it is assumed that a decrease of the same magnitude would occur in frequency for the $\mathrm{W}$ direction. In order to assess the wave climate sensitivity under a slight but probable wind climatic change, the aforementioned suggested values were adopted in order to sketch a hypothetical future scenario. Considering these changes, future $\mathrm{E}$ wind frequencies and mean intensity for the $\mathrm{E}$ direction would increase by $5.5 \%$ and $0.49 \mathrm{~m} \mathrm{~s}^{-1}$, becoming $23.9 \%$ and $5.4 \mathrm{~m} \mathrm{~s}^{-1}$ respectively. The total decrease in frequencies for the westerly directions (NW, W and SW) would be $5.5 \%$, compensating the predicted increase in the $\mathrm{E}$ direction. The mean height and period for the $\mathrm{E}$ direction are $1.02 \mathrm{~m}$ and $5.5 \mathrm{~s}$, as computed by the methodology explained in Section 3.3 based on the suggested future intensity. By replacing the estimated figures for the E direction in Equations (2) and (3), the future mean wave condition 
is described by a mean height of $0.59 \mathrm{~m}$ and a mean period of $3.6 \mathrm{~s}$, which means increases of $13 \%$ and $9 \%$ respectively with respect to the present values.

\section{SUMMARY AND DISCUSSION}

It was shown in Section 3.2 that both short and long swell coming from the outer RDP were strongly attenuated by refraction and bottom friction within the intermediate RDP, and hence the predominant wave climate in the upper RDP could only be described by considering wind waves generated locally (sea). The present wave climate (directional wave heights and periods) was estimated using the hindcasting methodology given by CERC $(1984,2002)$ based on 10-year statistics of winds measured at 'Aeroparque Jorge Newery' meteorological station (SMN, 1992). Next, a possible future scenario was sketched for which wind frequencies and intensities for the easterly directions were respectively $30 \%$ and $10 \%$ higher than the present values. Wind frequencies for the westerly directions were lower in this scenario in proportion to the easterly increases, meaning that the rest of the directions remained unchanged. This hypothetical future scenario has been supported by recent preliminary results of GCM scenarios (Barros, 2003). Our results showed that, mean E wave height and mean total wave height would increase within the upper RDP. The present mean E wave heights $(0.90 \mathrm{~m})$ would increase by $0.12 \mathrm{~m}(13 \%)$ and their frequencies would increase by $30 \%$ (from 18.4 to $23.9 \%$ ). Consequently, the coast of Buenos Aires city would be more frequently exposed to height wave effects, therefore giving rise to intensified associated littoral processes. Given the predominant orientation of the coast of Buenos Aires (NW-SE), the northwestward long-shore current and along-shore sediment transport would increase, producing both accretion of sediments upstream of the structures and erosion of the shore downstream of the coastal emplacements. The mean period for $\mathrm{E}$ waves would not change significantly (less than $4 \%$, from 5.3 to $5.5 \mathrm{~s}$ ).

In addition, we estimated a difference of $+0.07 \mathrm{~m}$ (from 0.52 to $0.59 \mathrm{~m}$ ) between present and future total (non-directional) mean wave height, which means an increase of $13 \%$. The mean period for the total mean wave would be $9 \%$ greater $(0.3 \mathrm{~s})$ than the present value (from 3.3 to $3.6 \mathrm{~s}$ ). Differences between present and future heights would have a significant effect over the energy density due to the quadratic relation between wave energy and wave height. The total average energy per unit surface area is proportional to $H_{\mathrm{MO}}^{2}$ (Dean and Dalrymple, 1984). The quotient between the future and the present total average energy is 1.29. This means that energy could increase by $29 \%$ under this future scenario of climatic change. An increase in the mean wave energy would imply a higher capability of water to maintain sediments suspended within the water column and, thus, an increase in the suspended sediment transport, which could modify the sediment transport dynamics affecting the deposition rates.

The results obtained here are a first approximation to the problem, and suggest that wave climate within the upper RDP could be sensitive to a slight change in the wind field. In consequence, major efforts should be directed to evaluating possible future changes by considering different scenarios. The potential impacts of future changes in the wave climate need to be assessed. Numerical modelling, including of wave generation and transformation, of realistic bathymetry, and of tides and currents, is a very powerful tool in order to assess possible changes in the wave climate under hypothetical atmospheric future conditions resulting from specific climatic studies. Likewise, decision makers should thoroughly consider the possible impacts on the coast of Buenos Aires city.

\section{ACKNOWLEDGEMENTS}

The work in this paper was funded by the AIACC, a project of the GEF implemented by the UNEP and co-executed by START and the TWAS and Project UBA X442-2003.

\section{REFERENCES}

Anschütz G. 2000. Comparison between SAR-ERS and Waverider Buoy meaurements in the outer Rio de la Plata estuary. In Coastal Wave Meeting, 25-28 September, Barcelona, Spain. 
Bacon S, Carter DJT. 1991. Wave climate changes in the North Atlantic and North Sea. International Journal of Climatology 11: $545-558$.

Bacon S, Carter DJT. 1993. A connection between mean wave height and atmospheric pressure gradient in the North Atlantic. International Journal of Climatology 13: 423-436.

Balay MA. 1961. El Río de la Plata entre la atmósfera y el mar. Publicación H-621. Servicio de Hidrografía Naval, Armada Argentina, Buenos Aires.

Barros V. 2003. Observed Plata River level change and wind field change: attribution and MCG scenarios. In First Latin American and Caribbean Regional AIACC Workshop, May, San José, Costa Rica.

Bouws E, Gunther H, Vincent CL. 1985. Similarity of wind wave spectrum in finite depth water, part I: spectral form. Journal of Geophysical Research 85(C3): 1524-1530.

CARP. 1992. Determinación del clima de olas en el Río de la Plata. Universidad Nacional de La Plata, Informe Técnico.

CERC. 1984. Wave and Water Level Prediction. In Shore Protection Manual, Ch. 3, vol. 1. US Government Printing Office Washington DC; $1-143$.

CERC. 2002. Meteorology and Wave Climate. In Coastal Engineering Manual, Ch. 2, vol. 2. US Army Coastal Engineering Research Center; $1-72$.

Cotton PD, Carter DJT. 1994. Cross-calibration of TOPEX, ERS-1, and Geosat wave heights. Journal of Geophyscal Research 99(C12): $25025-25033$.

Cox AT, Swail VR. 2001. A global wave hindcast over the period 1958-1997: validation and climatic assessment. Journal of Geophysical Research 106(C2): 2313-2329.

Datawell. 1997. Manual for the Waverider. Laboratory for Instrumentation: LM Haarlem, The Netherlands.

Dean RG, Dalrymple RA. 1984. Water Wave Mechanics for Engineers and Scientists. Prentice-Hall: Englewood Cliffs, NJ.

Dragani WC, Mazio CA. 1991. Refracción de olas. Depto. Oceanografía, Servicio de Hidrografía Naval, Buenos Aires, Informe Técnico nro. 61/91.

Escobar G, Camilioni I, Barros V. 2003. Desplazamiento del Anticiclón Subtropical del Atlántico Sur y su relación con el cambio de vientos sobre el estuario del Río de la Plata. In II Congreso Cubano de Meteorología y X Congreso Latinoamericano de Meteorología, 3-7 March, La Habana, Cuba.

Griswold GM. 1963. Numerical calculation of wave refraction. Journal of Geophysical Research 68(6): 1715-1723.

Gulev SK, Grigorieva V, Sterl A, Woolf D. 2003. Assessment of the reliability of wave observations from voluntary observing ships: insights from the validation of a global wind wave climatology based on voluntary observing ship data. Journal of Geophysical Research 108(C7): 3236. DOI: 10.1029/2002JC001437.

Hasselmann K, Ross DB, Muller P, Sell W. 1976. A parametric wave prediction model. Journal of Physical Oceanography 6: 200-228.

Putnam JA, Johnson JW. 1942. The dissipation of wave energy by bottom friction. Transactions of the American Geophysical Union 30(1): $67-74$.

SHN. 1999a. Río de la Plata Medio y Superior, Carta Náutica H116, 4th edn. Servicio de Hidrografia Naval, Armada Argentina, Buenos Aires.

SHN. 1999b. Río de la Plata Exterior, Carta Náutica H113, 2nd edn. Servicio de Hidrografia Naval, Armada Argentina, Buenos Aires. SMN. 1992. Estadísticas climatológicas 1981-1990, Serie B, Nro. 37. Servicio Meteorológico Nacional, Fuerza Aérea Argentina, Buenos Aires.

Sterl A, Komen GJ, Cotton PD. 1998. Fifteen years of global wave hindcasts using winds from the European Centre for Medium-Range Weather Forecasts reanalysis: validating the reanalyzed winds and assessing the wave climate. Journal of Geophysical Research 103(C3): 5477-5492.

Vincent C. 1985. Depth-controlled wave height. Journal of Waterway, Port, Coastal and Ocean Engineering 111(3): 459-475.

Vincent C, Carrie A. 1988. Evaluation of an energy-propagation wave refraction model. Continental Shelf Research 8(3): 287-305.

Watanabe A. 1982. Numerical modelling of nearshore currents and beach deformation. Coastal Engineering in Japan 25: 147-161.

Wilkerson JC, Earle MD. 1990. A study of differences between environmental reports by ships in the voluntary observing program and measurements from NOAA buoys. Journal of Geophysical Research 95(C3): 3373-3385.

Woolf DK, Challenor PC, Cotton PD. 2002. Variability and predictability of the North Atlantic wave climate. Journal of Geophysical Research 107(C10): 3145-3158. Doi: 10.1029/2001JC001124. 